\title{
Non-syndrome patient with bilateral supernumerary teeth: Case report and 9-year follow-up
}

\author{
Ozlem Marti Akgun' \\ Fidan Sabuncuoglu² \\ Ayberk Altug ${ }^{3}$ \\ Ceyhan Altun ${ }^{1}$
}

\begin{abstract}
The presence of supernumerary teeth, also known as hyperdontia, is the condition of having teeth in addition to the regular number of teeth. The occurrence of multiple supernumerary teeth is often found in association with syndromes such as Gardner syndrome, Anderson-Fabry disease, Ellis-van Creveld syndrome, Ehlers-Danlos syndrome, incontinentia pigmenti, and Tricho-rhino-phalangeal syndrome. Only a few examples of nonsyndromic multiple supernumerary teeth have been reported in literature. In this report, we present the unusual case and 9-year follow up of a non-syndrome female patient with bilateral supernumerary teeth that occurred with an interval of several years. (Eur J Dent 2013;7:123-126)
\end{abstract}

Key words: Supernumerary teeth; non-syndrome; bilateral supernumerary teeth

\section{INTRODUCTION}

Supernumerary teeth may be defined as any teeth or tooth substance in excess of the usual configuration of 20 deciduous and 32 permanent teeth. ${ }^{1}$ The etiology of supernumerary teeth is not completely understood. Various theories exist for the different types of supernumerary teeth. ${ }^{2}$ One of the theories proposes that the supernumerary

1 Department of Pediatric Dentistry, Central of Dental Sciences, Gulhane Medical Academy, Ankara, TURKIYE

2 Department of Orthodontics, Maresal Fevzi Cakmak Hospital, Erzurum, TURKIYE

3 Department of Oral and Maxillofacial Surgery, Central of Dental Sciences, Gulhane Medical Academy, Ankara, TURKIYE

- Corresponding author: Dr. Ceyhan Altun Department of Pediatric Dentistry, Centre of Dental Sciences, Gulhane Medical Academy, Etlik, Ankara, TURKIYE

Tel: +90 3123046041 Fax: +90 3123046020

Email: ceyhanaltundyahoo.com tooth is produced because of a dichotomy of the tooth bud. ${ }^{3}$ Another theory-the hyperactivity theory-suggests that they are formed because of local, independent, conditioned hyperactivity of the dental lamina. ${ }^{4}$ Genetics may also influence the development of supernumerary teeth. ${ }^{5}$

Supernumerary teeth may be classified based on form (conical type, tuberculate type, supplemental type, odontome) or position (mesiodens, paramolar, distomolar, parapremolar). ${ }^{6}$ The clinical complications of supernumerary teeth include root anomaly, malocclusion, root resorption, displacement or rotation, failure of eruption or delayed eruption of adjacent tooth, cyst formation, and pulp necrosis with loss of vitality and esthetic disturbances.?

The most common supernumerary teeth, listed in order of frequency, are the maxillary midline su- 
pernumeraries (mesiodens), maxillary fourth molars, maxillary paramolars, mandibular premolars, maxillary lateral incisors, mandibular fourth molars, and maxillary premolars. ${ }^{8}$

The occurrence of multiple supernumerary teeth is often found in association with syndromes such as Gardner's syndrome, Fabry Anderson Syndrome, Ellis Van Creveld Syndrome, Ehlers Danlos Syndrome, Incontinentia Pigmenti and TrichoRhino-Phalangeal Syndrome and developmental disorders such as Cleft lip and palate and Chondroectodermal dysostosis. ${ }^{9}$ The presence of supernumerary teeth may be associated with familial tendency. ${ }^{10}$ Only a few examples of long-term follow-up of nonsyndromal bilateral supernumerary teeth have been reported in the literature. ${ }^{11}$ The aim of this study is to present an unusual case of a non-syndrome female patient with bilateral supernumerary teeth which occurred with an interval of several years.

\section{CASE REPORT}

A 9-year-old female patient presented to our clinic complaining of pain in her primary teeth. Medical and family histories were unremarkable. An intraoral examination showed that the patient had a Class I canine relationship on the right and left side and bilateral posterior crossbite due to bilateral constriction of the maxilla. Overjet and overbite were normal (Figure 1a). A panoramic survey of the teeth showed an unerupted supernumerary tooth that was located on the left side of the maxillary arch (Figure 1b). A standard maxillary occlusal radiograph was taken to determine the position of the unerupted tooth. The radiograph showed that the tooth was in a palatal position (Figure 1c). Following local anesthesia, a sulcular incision was performed and the supernumerary tooth was extracted via a palatal approach. The patient refused fixed orthodontic treatment and it was decided to observe the teeth and review the patient during the follow-up period. In the second follow-up period, after 3 years, radiographic examination revealed the presence of an unerupted supernumerary tooth in a palatal position on the right side of the maxillary arch (Figure $1 \mathrm{~d}$ ). The tooth was removed as described above under local anesthesia (Figure 1e). Presently, the patient is followed up through periodic examinations (Figure $1 \mathrm{f}$.

\section{DISCUSSION}

Supernumerary teeth can be defined as the teeth present in addition to the normal set of teeth. Rajab and Hamdam ${ }^{12}$ reported that the most frequent supernumerary teeth identified were me-

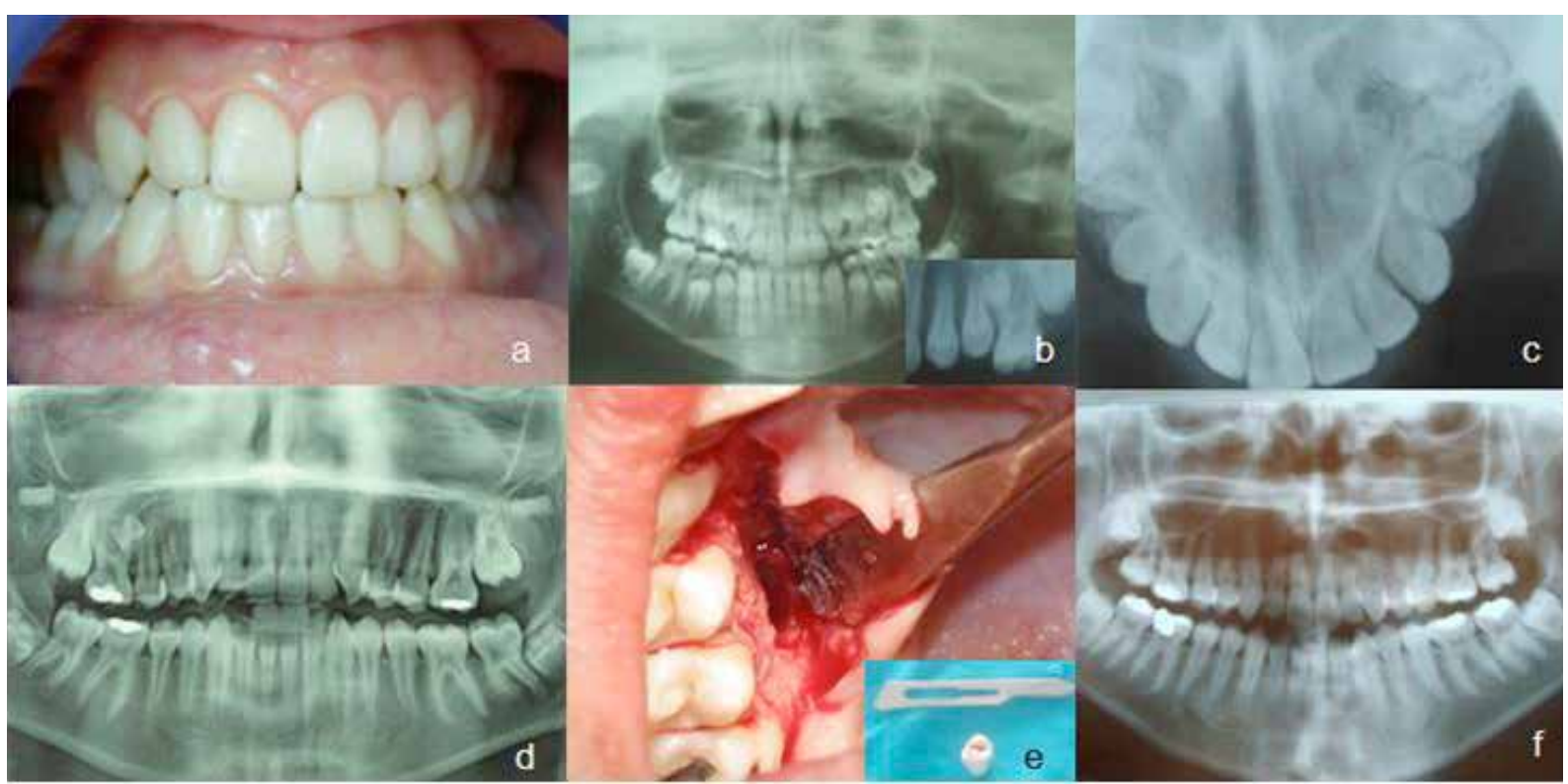

Figure 1. (a) Intraoral appearance of the patient. Overjet and overbite were normal, (b) Panoramic and periapical survey of the teeth showed unerupted supernumerary tooth which was located on the left side of the maxillar arch, (c) Occlusal radiograph which showed the supernumerary tooth was in palatal position, (d) Two years after the surgery radiographic examination revealed the presence of an unerupted supernumerary tooth on the right side of maxillar arch, (e) Supernumerary tooth were extracted via palatal approach, (f) Panoramic radiography which taken nine years after preliminary surgical application. 
siodens, followed by premolars, and fourth molars or distal molars. However, authors such as Menardía et $\mathrm{al}^{13}$ reported that the supernumerary teeth of the molar group are the most prevalent type in the general population. In the present case, 2 supernumerary premolar teeth were located on the left and right side of the maxillary arch.

Supernumerary teeth are considered one of the most common dental anomalies, affecting the primary and early mixed dentition. ${ }^{12}$ The etiology of supernumerary teeth remains unclear, but several theories have been suggested for their occurrence. The localized and independent hyperactivity of the dental lamina is the most accepted cause for the development of supernumerary teeth. Some have proposed that supernumerary teeth are formed as a result of local, independent, and conditioned hyperactivity of the dental lamina. ${ }^{14}$

The incidence of supernumerary teeth is reported to be between 0.1 and $3.6 \%$ of the general population. ${ }^{15}$ Rajab and Hamdan ${ }^{12}$ reported in their study that males were more frequently affected than females (sex ratio, 2.2:1). Mitchell ${ }^{16}$ reported a 2:1 ratio in favor of males. Altug et $\mathrm{al}^{17}$ concluded that males are much more frequently affected than females with a 1.25:1 ratio. Supernumerary teeth are more likely to be present in patients whose relatives possessed supernumeraries, although the inheritance of these teeth does not follow a simple Mendelian pattern. ${ }^{18}$ Batra et $\mathrm{al}^{5}$ recently reported the presence of multiple supernumerary teeth occurring as a nonsyndromic trait in a girl, her elder brother, and her father.

In reviewing the literature, only a few cases of multiple supernumerary teeth were found without any associated syndromes or systemic disorders. ${ }^{5,8,10,19}$ In the present case, a non-syndrome female patient with bilateral supernumerary teeth was present. What is important is that this paper reports a case of nonsyndromic bilateral supernumerary teeth.

The importance of the use of a panoramic radiograph to evaluate a patient's condition is emphasized whenever a supernumerary tooth is detected, irrespective of whether the patient has any syndrome or not. ${ }^{19}$ We observed the first supernumerary tooth during routine panoramic radiogra- phy by chance. The second supernumerary tooth was noticed during the follow-up period. This case also shows how important the follow-up period is.

Whenever supernumerary teeth are diagnosed, single or multiple, a decision regarding appropriate management should be carefully considered. Surgical removal of the teeth may cause damage to adjacent structures ${ }^{12}$. Spontaneous eruption following supernumerary removal is suggested to be in the range of $54-75 \% .{ }^{20}$ DiBiase ${ }^{21}$ has suggested that most teeth experiencing delayed eruption will spontaneously erupt within 18 months of supernumerary removal alone, provided the delayed tooth is not excessively displaced. Timing of surgical removal of supernumerary teeth has also been contentious. Hogstrum and Andersson ${ }^{22}$ have suggested that 2 alternatives exist. The first option involves removal of the supernumerary as soon as it has been diagnosed. This could create dental phobia problems for a young child and has been reported to cause devitalization or deformation of adjacent teeth. Secondly, the supernumerary tooth could be retained until root development of the adjacent teeth is complete. The potential disadvantages associated with this deferred surgical plan include loss of eruptive force of adjacent teeth, loss of space and crowding of the affected arch, and possible midline shifts. Obviously, the position, size, and nature of the supernumerary tooth and the level of co-operation of the patient will influence the surgical difficulty; hence, each case should be individually assessed. In our opinion, it is important to initiate appropriate consultation and an interdisciplinary approach for treatment.

\section{CONCLUSION}

In this paper we report a case of nonsyndromic bilateral supernumerary teeth. Additionaly; we emphasized that in cases of supernumerary teeth the follow-up period and interdisciplinary approach are very important for treatment.

\section{REFERENCES}

1. Schulze C. Developmental abnormalities of teeth and jaws. In Gorlin RJ, Goldman HM (eds). Thoma's Oral Pathology St Louis: CV mosby 1970; 112-122. 
2. Garvey MT, Barry HJ, Blake M. Supernumerary Teeth -An Overview of Classification, Diagnosis and Management. $J$ Can Dent Assoc 1999;65 612-616.

3. Liu JF. Characteristics of premaxillary supernumerary teeth: a survey of 112 cases. ASDC J Dent Child 1995;62:262265.

4. Levine N. The clinical management of supernumerary teeth. J Can Dent Assoc 1961;28:297-303.

5. Batra P, Duggal R, Parkash H. Non-syndromic multiple supernumerary teeth transmitted as an autosomal dominant trait. J Oral Pathol Med 2005;34:621-625.

6. Ramsaran AS, Barclay S, Scipio E, Ogunsalu C. Non-Syndromal Multiple Buried Supernumerary Teeth. West Indian Med J 2005;54:334-336.

7. Shetty R, Sandler PJ. Keeping your eye on the ball. Dent Update 2004;31:398-402.

8. Türkkahraman $H, Y_{ı} l$ maz $H H$, Çetin $E$. A non syndrome case with bilateral supernumerary canines: report of a rare case. Dentomaxillofac Radiol 2005;34:319-321.

9. Moore SR, Wilson DF, Kibble J. Sequential development of multiple supernumerary teeth in the mandibular premolar region-a radiographic case report. Int $J$ Paediatr Dent 2002;12:143-145.

10. Nayak UA, Mathian VM. Non-syndrome associated multiple supernumerary teeth: A report of two cases. J Indian Soc Pedod Prev Dent 2006; special issue:11-14.

11. Shashikiran ND, Reddy VVS, Mandroli P. Molariform supernumerary tooth-a case report. J Indian Soc Pedo Prev Dent 2000;18:18-20.

12. Rajab LD, Hamdan MA. Supernumerary teeth: review of the literature and a survey of 152 cases. Int J Peadiatr Dent 2002;12:244-254

13. Menardía-Pejuan V, Berini-Aytés L, Gay-Escoda C Supernumerary molars. A review of 53 cases. Bull Group Int Rech Sci Stomatol Odontol 2000;42:101-105.

14. Primosch R. Anterior supernumerary teeth-assessment and surgical intervention in children. Pediatr Dent 1981;3:204-215.

15. Yusof WZ. Non-syndromal multiple supernumerary teeth: literature review. J Can Dent Assoc 1990;56:147-149.

16. Mitchell L. Supernumerary teeth. Dent Update 1989;16:6569.

17. Altug HA, Altug H, Sari E, Șençimen M, Altun C. Diagnosis and surgically-ortodontically management of supernumerary teeth in both the primary and the permanent dentitions. GÜ Diş Hek Fak Derg 2010;27:77-82.

18. Marya CM, Kumar BR. Familial occurrence of mesiodentes with unusual findings: case reports. Quintessence Int 1998;29:49-59.
19. Umweni AA, Osunbor GE. Non-syndromal multiple supernumerary teeth in Nigerians. Odontostomatol Trop 2002;25:43-48.

20. Gündüz K, Muglali M. Non-syndrome Multiple Supernumerary Teeth: A Case Report. $J$ Contemp Dent Pract 2007;4:81-87.

21. DiBiase D. The effects of variations in tooth morphology and position on eruption. Dent Pract 1971;22:95-108.

22. Hogstrum A, Andersson L. Complications related to surgical removal of anterior supernumerary teeth in children. $J$ Dent Child 1987;54:341-343. 